\title{
Effects of early sensory deprivation on spatial learning in adult rats
}

\author{
Natalia Kurzina, Irina Aristova, and Anna Volnova \\ Faculty of Biology, Saint Petersburg State University, \\ Universitetskaya nab., 7-9, Saint Petersburg, 199034, Russian Federation \\ Address correspondence and requests for materials to Natalia Kurzina,n.kurzina@spbu.ru
}

\begin{abstract}
Following vibrissae removal in early ontogenesis from P1 (post-natal day 1 ) to P30, three-month old rats were trained to run for food in an 8-arm radial maze. Training started at the age of three months. Adult rats demonstrated ability to perform the behavioral task; however, their performance was not as good as in the control group. Our findings revealed the differences in the rats 'exploratory strategy and key behavioral tactics of entering the maze arms at a certain angle. The results show that active vibrissae sensing plays an important role in shaping rat behavioral tactics during spatial learning in the 8-arm radial maze.

Keywords: ontogenesis, behavior, vibrissae, sensory deprivation, spatial learning.
\end{abstract}

\section{Introduction}

Studies into sensory deprivation in early ontogenesis yield extensive information concerning the formation of functional systems underlying adaptive behaviors (Raevskii et al., 1997).

Numerous investigations have been made of the sensory deprivation effects on the developing organism. However, most studies have focused on revealing the structural changes in the neural tissue and the impacts thereof (Allen, Celikel, and Feldman, 2003; Korneeva and Shuleǐkina, 1999; Sadaka, Lev, Weinfeld, and White, 2000; Sitnikova, 2001, 2010).

Overviews in the literature report various behavioral models used to investigate effects of various types of sensory deprivation on behavior during early

Citation: Kurzina, N., Aristova, I., and Volnova, A. 2017. Effects of early sensory deprivation on spatial learning in adult rats. Bio. Comm. 62(4): 256-260. https://doi. org/10.21638/11701/spbu03.2017.404

Author's information: Natalia Kurzina, Ph.D., Senior Lecturer, orcid.org/0000-00029205-713X; Irina Aristova; Anna Volnova, Dr. Sci., orcid.org/0000-0003-0724-887X

Manuscript Editor: Alla Ignashchenkova, Hertie Institute for Clinical Brain Research Tuebingen, Germany;

Received: January 10, 2018;

Revised: March 09, 2018.

Accepted: March 14, 2018;

Copyright: @ 2017 Kurzina et al. This is an open-access article distributed under the terms of the License Agreement with Saint Petersburg State University, which permits to the authors an unrestricted distribution and self-archiving free of charge.

Funding: No funding information provided. Competing interests: The author has declared that no competing interests exist. development (Korneeva, Aleksandrov, Golubeva, and Raevskii, 2010; Shishelova, 2006; Shishelova and Raevskii, 2010; Shishelova, Aliev, and Raevskii, 2016).

However, data providing evidence for the consequences of early sensory deprivation for memory and learning are limited (Grigoryan, Hodges, and Gray, 2005; Papaioannou, Brigham, and Krieger, 2013; Symons and Tees, 1990).

An assessment was made of the consequences of selective early sensory deprivation on the spatial behavior of the adult rat. The aim of this study was to investigate the behavioral effects of early bilateral vibrissal removal (trimming) on spatial learning in adult rats.

\section{Methods}

29 vivarium reared Wistar male rats with a body weight of 200-250 g were used in this study. Food (PK 120, RF, GOST P50258-92) and water were freely available. The experiments were conducted in compliance with The Regulations on Research Using Experimental Animals (Order of Ministry of Health of USSR\#755 of 12.08.1977), FELASA and RusLAS rules regarding work with laboratory animals. Day of birth was P0 when the handling of the neonates started. 
Prior to training in an 8 -arm radial maze, the experimental group (14 rats) was subjected to bilateral vibrissae removal (by trimming the mystacial vibrissae daily from P1 to P30, without damaging the skin). Rearing environment for other non-deprived rats (15 rats, the control group) was normal, with a daily routine of 2-3 minutes handling like in the experimental group.

At the age of 3 months, both groups were trained daily after 14:00 in a radial 8-arm maze for 12 days. Rats received food at a ratio of $80 \%$ of their regular diet. Normal new whiskers had regrown in all rats by the beginning of the training sessions.

An elevated 8-arm radial maze was used for spatial training. Maze dimensions were as follows: a $39 \mathrm{~cm}$ diameter central arena with eight $5 \mathrm{~cm}$ high entries to the eight arms (length $30 \mathrm{~cm}$, width $10 \mathrm{~cm}$, height $9 \mathrm{~cm}$ ). The maze arms were numbered 1 to 8 clockwise. The maze was placed $55 \mathrm{~cm}$ above the floor level. Prior to the experiment, food reward was placed in all 8 arms (even reward distribution). Popcorn breakfast loops (produced by Nestle) were used as a reward (half of a loop in each food box; weight $0.2 \mathrm{~g}$ ).

The rats were trained as follows: Each training session started with the rat being placed on the arena with its head to arm No. 5 and its tail to arm No. 1. Rats tended to move from the arena to one of the arms, then return to the arena along the same arm to choose another arm. The training session was considered complete after the rat had visited all eight arms containing a reward. A re-visit to the same arm was considered erroneous. Sequences of the maze arms visited were recorded. Rats received an additional reward at the end of a training session. Each rat was trained in one experiment daily.

During the initial two days of pre-training and familiarizing with training conditions, revisits of arms were rewarded.

Prior to a training session, the maze was treated with peroxidase chloride in order to remove any odor traces.

The data were processed starting from the training session on Day 3 after rats had visited all 8 maze arms, with revisits to the same corridor considered erroneous. The following behavioral parameters were measured:

(1) Index of correct trials (ICT) - the number of correct entries during each experimental day for both groups of animals; was calculated as a percentage ratio of correct entries to the total number of entries. The performance was considered successful when $85-95 \%$ correct entries occurred.

(2) The number of correct entries (NCE) before the first erroneous entry occurred, as an index of working memory

(3) The angle of subsequent arm visit. Adjacent arms in the eight-arm maze are positioned at $45^{\circ}$, and the arm that the rat visited after leaving the previous one was recorded. This allowed us to evaluate the dynamics of the tactics used by animals in order to minimize efforts for food procuring.

Statistical data were presented as a mean value \pm error of mean. Preliminary estimation of data distribution normality (Gaussian distribution) was done using the Kolmogorov-Smirnov test. Differences across groups were estimated by the t-test for independent samples. The analysis of variance (two-way ANOVA) was also used, $p<0.05$ was considered statistically significant for all tests.

\section{Results}

Data analysis showed that in both groups the ratio of correct entries reached $80-85 \%$ from the third experimental day onwards, and 90-95\% correct entries occurred by the tenth experimental day (Fig. 1). Cumulative analysis of ICT dynamics by two-way ANOVA showed that both groups demonstrated positive learning dynamics (two-way ANOVA, time factor, $p<0.001$ ). However, the control group performed the behavioral task more efficiently (two-way ANOVA, group factor, $p<0.05$ ) than rats which had undergone vibrissae removal (Fig. 1).

Spatial learning in a radial maze requires the involvement of working memory processes. Assessment of the number of correct entries made by the rats before the first erroneous trial occurred (Fig. 2) showed that despite a positive performance progress that occurred in both groups with training (two-way ANOVA, time factor, $p<0.001$ ), this parameter related to the working memory is considerably higher (two-way ANOVA, group factor, $p<0.001$ ) in the control rats.

These data provide evidence that removal of the vibrissae at an early age does impact rats 'spatial capacities in the adult age. Rats that had undergone vibrissae removal performed less efficiently as compared to the controls.

An assessment was also made of the angle of subsequent arm visits in the radial maze. This parameter provided the most significant differences between the control group and the experimental group (Fig. 3). Our results showed that the control rats frequented $(0.39 \pm$ 0.02 ) arms located at $45^{\circ}$ to the arms they had just left, and entries at $90^{\circ}$ occurred less frequently $(0.32 \pm 0.01$, $p<0.05$ ) (Fig. 3a). Rats from the vibrissae removal group showed reliably less frequent entries to arms at $45^{\circ}$ than at $90^{\circ}(0.20 \pm 0.02$ and $0.39 \pm 0.02$ accordingly, $p<0.0001$, Fig. 3b).

Probabilities of angles of subsequent arm visits were examined in both groups, and reliable differences between control and experimental rats were demonstrated (Figs. 3a, 3b). Control rats more frequently visited arms located at $45^{\circ}$ to the previously visited arm, thus opti- 


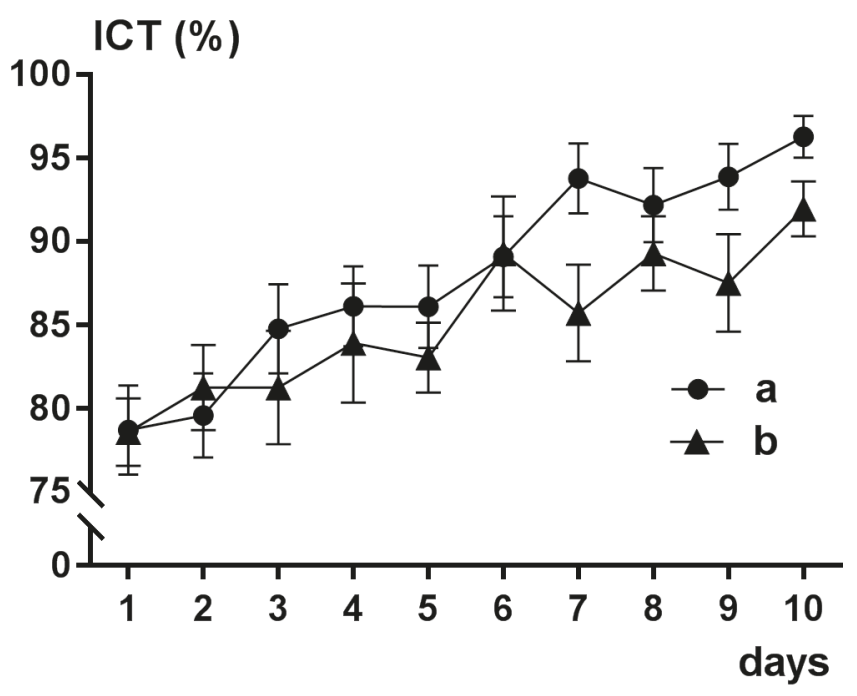

Fig. 1. Dynamics of the correct trial number (index of correct trials, ICT) in the control group (a) and in the post-vibrissae removal group (b). The abscissa - training days, the ordinate - correct trial number (mean \pm SEM, \%).

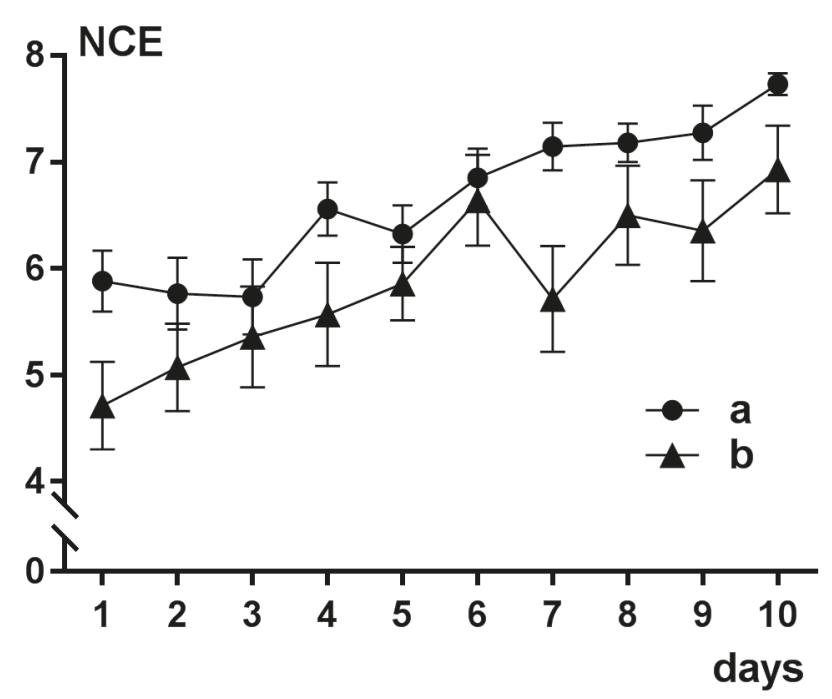

Fig. 2. Dynamics of the correct entries number before first error (number of correct entries, NCE) in the control group (a) and the post-vibrissae removal group (b). The abscissa - training days, the ordinate - correct trial number before a first error occurred (mean $\pm \mathrm{SEM})$.

mizing tactics of procuring a food reward. In contrast, the experimental rats showed a reliable preference of visiting arms at $90^{\circ}$. Thus, the tactics of subsequent arm visit revealed reliable differences between the experimental and control groups.

\section{Discussion}

Several studies have indicated the important role played by active vibrissal sensing from an early age in locomotion and exploratory behavior (Arkley, Grant, Mitchinson, and Prescott, 2014; Grant, Mitchinson, and Prescott, 2012; Shishelova, Aliev, and Raevski, 2016).

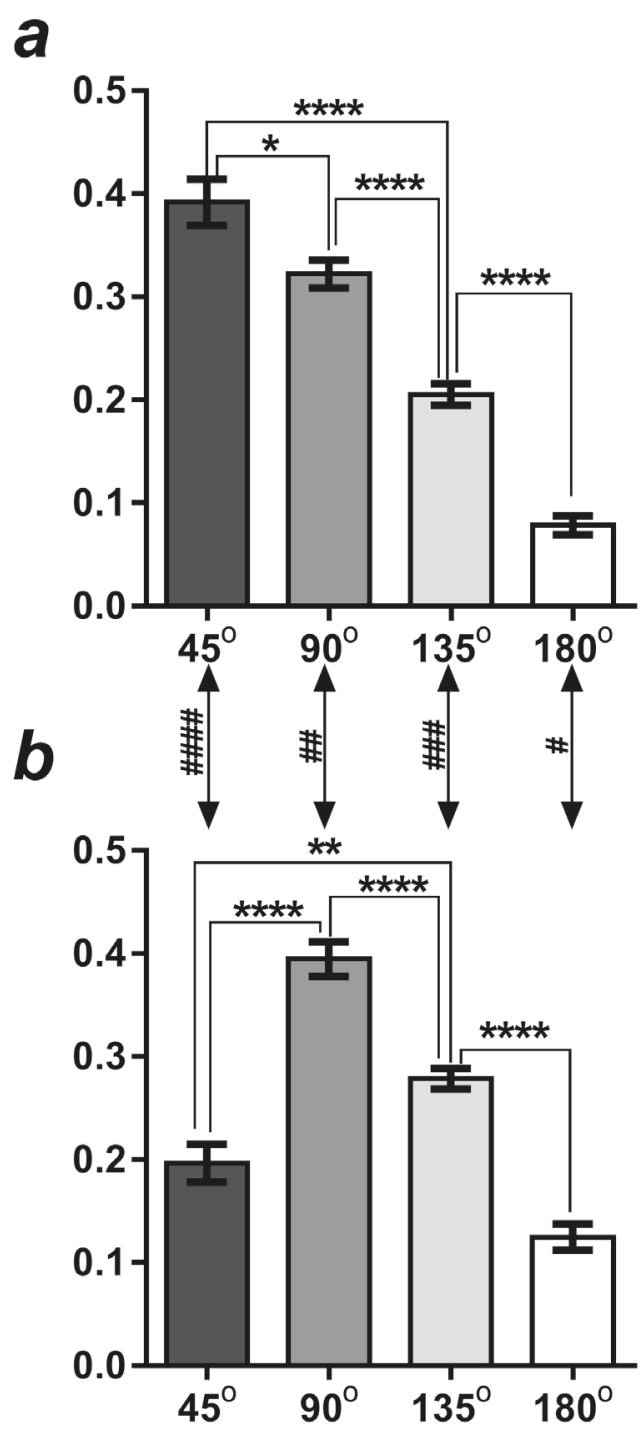

Fig. 3. Probabilities of arm entries in the control group (a), and the post-vibrissae removal group (b). The abscissa - the angles, the ordinate - probability of arm entries at a certain angle (mean $\pm \mathrm{SEM}$,), black columns represent the data for $45^{\circ}$; dark grey $90^{\circ}$; grey $-135^{\circ}$; white $-180^{\circ}$ (straight runs). Statistically significant differences in mean values (to the Student's t- test): * $-p<$ 0.05; ** $-\mathrm{p}<0.01$; **** $-\mathrm{p}<0.0001$; \# $-\mathrm{p}<0.05$; \#\# $-\mathrm{p}<$ $0.01 ; \# \# \#-p<0.001 ; \# \# \# \#-p<0.0001$.

Recently published overviews provide evidence for the role of vibrissal touch sensing and head movements in spatial exploratory behavior and analysis of tactile information (Feldmeyer et al., 2013; Hobbs, Towal, and Hartmann, 2015; Huet, Schroeder, and Hartmann, 2015). Specific characteristics of somatosensory cortex activity have been revealed in the investigations of rat exploratory behavior and the active whisking behavior in orientation and search for rats' home area (Ganguly and Kleinfeld, 2004; Petersen, 2007).

There is evidence to suggest that formation of neural connections of the somatosensory cortex is a consequence of competition between adjacent inputs from 
separate vibrissae to the cortical areas (Mitrukhina, Suchkov, Khazipov, and Minlebaev, 2015). Early sensory deprivation following the removal of the peripheral vibrissae affects the overall somatosensory cortex development with a deterioration of synaptic connections between the deprived and non-deprived zones (Petersen, Brecht, Hahn, and Sakmann, 2004). In this case, the columnar organization of the somatosensory cortex might be affected, resulting in the death of neurons and a decrease in the dendritic tree ramification and thalamic input fibers (Feldmeyer et al., 2013).

Also, it was revealed that a complete bilateral vibrissae removal from P0 for three days leads to profound behavioral deficits later in life (Erzurumlu, 2010).

The influences of vibrissae sensory deprivation on behavioral performances were studied in adult rats in the Morris test. Since the rats without vibrissae stayed by the platform considerably longer, it was suggested that vibrissae contribute to the proprioceptive control of the platform location (Grigoryan, Hodges, and Gray, 2005). Following vibrissae removal from P9 to P20, the rats showed a decrease in exploratory behavior in the open field test when compared with the control group (Shishelova, Aliev, and Raevskii, 2016).

Some findings suggest that vibrissae removal in rats has long-lasting effects on the development of the cortical formations (Shishelova and Raevskii, 2010; Shishelova, Aliev, and Raevskii, 2016); these results point to the consequences and difficulties in performing spatial tasks even after the regrowth of normal vibrissae.

Our results revealed reliable differences between the control and the experimental groups in the tactics of subsequent arm visits at a certain angle. This fact might be related to early damage of the somatosensory cortex connections with the neural structures that control rat location in space and provide for body schema and posture in space (Feldmeyer et al., 2013).

We showed earlier that preference to visit maze arms at $45^{\circ}$ is typical for all rats and may be changed after a special influence (Batuev, Kurzina, and Paranina, 2007; Kurzina, Batuev, and Paranina, 1999). Our recent results compared learning in an 8-arm maze in onemonth old rats and four-month old rats. Only adult rats preferred to visit maze arms at $45^{\circ}$, whereas the young rats failed to follow these behavioral tactics and showed reliable differences in visiting the arms at $90^{\circ}$ more frequently (Kurzina, Aristova, and Volnova, 2018).

Thus, altered maturation of the somatosensory cortex and lack of spatial behavioral experience, resulting from early vibrissae removal in young rats, might affect formation of optimal tactics for subsequent arm visits at a certain angle, which is typical of adult rats.

The tactics of visiting the next arm at a certain angle appear to be connected with the egocentric behavioral strategy and learning the way in the maze by active vi- brissae sensing of the maze walls and registering actual body posture in space. The hippocampal structures are known to play an important role in cognitive processes of spatial mapping and learning in a radial maze. For orientation in space, rats use allocentric and egocentric behavioral strategies for cognitive spatial mapping when learning in a radial maze. The egocentric strategies are related to memorizing environment and body posture, and vibrissae sensing is necessary for this purpose (Arkley, Grant, Mitchinson, and Prescott, 2014; Brecht et al., 2004).

It is known that vibrissae movements are involved in object shape description and distance to its localization (Knutsen, Pietr, Ahissar, 2006). These findings proved that sensorimotor feedback is essential for animal judgment about actual body position (Mehta et al., 2007). These data allow us to suppose that not only object localization but also use of behavioral tactics are based on normal vibrissae system functioning and, as a result, the external world model creation.

Tactile information flow and vibrissae tactile discrimination are requisite for the hippocampus to provide for spatial orientation and dynamic updates of spatial maps (Pereira et al., 2007). Early vibrissae removal affects the somatosensory cortex structure and connections underlying spatial orientation and body schema control and subsequently influences spatial-motor tactics during learning (Brecht et al., 2004; Feldmeyer et al., 2013).

Our results provide further evidence that early vibrissae removal in rats has long-term behavioral consequences, attenuating spatial learning in the 8-arm maze and changing adaptive behavior in search of food.

\section{References}

Allen C. B., Celikel T., and Feldman D. E. 2003. Long-term depression induced by sensory deprivation during cortical map plasticity in vivo. Nature Neuroscience 6(3):291-299. https://doi.org/10.1038/nn1012

Arkley K., Grant R.A., Mitchinson B., and Prescott T.J. 2014. Strategy change in vibrissal active sensing during rat locomotion. Current Biology 24(13):1507-1512. https://doi.org/10.1016/j.cub.2014.05.036

Batuev A. S., Kurzina N. P., and Paranina I. N. 2007. Dorsolateral thalamic nucleus destruction influence on alcoholic rat behavior in a radial maze. Biological Communications [s.l.] 3(2):76-85.

Brecht M., Krauss A., Muhammad S., Sinai-Esfahani L., Bellanca S., and Margrie T. W. 2004. Organization of rat vibrissa motor cortex and adjacent areas according to cytoarchitectonics, microstimulation, and intracellular stimulation of identified cells. Journal of Comparative Neurology 479(4):360-373. https://doi.org/10.1002/cne.20306

Erzurumlu R.S. 2010. Critical period for the whisker-barrel system. Experimental Neurology 222(1):10-12. https://doi.org/10.1016/j.expneurol.2009.12.025.

Feldmeyer D., Brecht M., Helmchen F., Petersen C. C., Poulet J. F., Staiger J. F., Luhmann H. J., and Schwarz C. 2013. Barrel cortex function. Progress in Neurobiology 103:327. https://doi.org/10.1016/j.pneurobio.2012.11.002. 
Ganguly K., and Kleinfeld D. 2004. Goal-directed whisking increases phase-locking between vibrissa movement and electrical activity in primary sensory cortex in rat. Proceedings of the National Academy of Sciences, USA 101(33):1234812353. https://doi.org/10.1073/pnas.0308470101

Grant R. A., Mitchinson B., and Prescott T.J. 2012. The development of whisker control in rats in relation to locomotion. Developmental Psychobiology 54(2):151-168. https://doi.org/10.1002/dev.20591

Grigoryan G., Hodges I. H., and Gray J. 2005. Effects of vibrissae removal on search accuracy in the water maze. Neuroscience and Behavioral Physiology 35(2):133-137.

Hobbs J.A., Towal R. B., and Hartmann M.J. 2015. Spatiotemporal patterns of contact across the rat vibrissal array during exploratory behavior. Frontiers in Behavioral Neuroscience 9:356. https://doi.org/10.3389/fnbeh.2015.00356

Huet L. A, Schroeder C. L, and Hartmann M. J. 2015. Tactile signals transmitted by the vibrissa during active whisking behavior. Journal of Neurophysiology 113(10):3511-3518. https://doi.org/10.1152/jn.00011.2015

Knutsen P. M., Pietr M., and Ahissar E. 2006. Haptic object localization in the vibrissal system: behavior and performance. Journal of Neuroscience 26(33):8451-8464. https://doi.org/10.1523/JNEUROSCI.1516-06.2006

Korneeva E. V., Aleksandrov L. I., Golubeva T.B., and Raevskii V. V. 2010. Effects of visual deprivation on the development of auditory sensitivity during formation of the freezing reaction in pied flycatcher nestlings. Neuroscience and Behavioural Physiology 40(5):479-482. https://doi.org/10.1007/s11055-010-9284-6.

Korneeva E. V. and Shuleǐkina K. V. 1999. The morphogenesis of Wulst neurons in the pied flycatcher under conditions of limited afferent inflow. Zhurnal Vysshey Nervnoy Deyatel'nosti I. P. Pavlova 49(3):495-504.

Kurzina N. P., Batuev A. S., and Paranina I. N. 1999. The influence of alcohol consumption on rat behavior in 8-arm radial maze. Zhurnal Vysshey Nervnoy Deyatel'nosti I. P. Pavlova 49(6):1027-1237.

Kurzina N., Aristova I., and Volnova A. 2018. Lateralization of motor reactions and formation of behavioural tactics during learning in the eight-arm radial maze in adolescent and adult rats. Laterality 23(1):101-112. https://doi.org/10.1080/1357650X.2017.1316284

Mehta S. B., Whitmer D., Figueroa R., Williams B. A., and Kleinfeld D. 2007. Active spatial perception in the vibrissa scanning sensorimotor system. PLoS Biology 5(2):309322. https://doi.org/10.1371/journal.pbio.0050015

Mitrukhina O., Suchkov D., Khazipov R., and Minlebaev M. 2015. Imprecise whisker map in the neonatal rat barrel cortex. Cerebral Cortex 25(10):3458-3467. https://doi.org/10.1093/cercor/bhu169
Papaioannou S., Brigham L., and Krieger P. 2013. Sensory deprivation during early development causes an increased exploratory behavior in a whisker-dependent decision task. Brain and Behavior 3(3): 24-34. https://doi.org/10.1002/brb3.102

Pereira A., Ribeiro S., Wiest M., Moore L. C., Pantoja J., Lin S. C., and Nicolelis M. A. 2007. Processing of tactile information by the hippocampus. Proceedings of the $\mathrm{Na}$ tional Academy of Sciences, USA 104(46):18286-18291. https://doi.org/10.1073/pnas.0708611104

Petersen C. C. 2007. The functional organization of the barrel cortex. Neuron 56(2):339-355. https://doi.org/10.1016/j. neuron.2007.09.017

Petersen C. C., Brecht M., Hahn T. T., and Sakmann B. 2004. Synaptic changes in layer 2/3 underlying map plasticity of developing barrel cortex. Science 304(5671):739-742. https://doi.org/10.1126/science.1096750

Raevskii V. V., Aleksandrov L. I., Vorob'eva A. D., Golubeva T. B., Korneeva E. V., Kudriashov I. E., Kudriashova I. V., Pigareva M. L., Sitnikova E. I., and Stashkevich I. S. 1997. Sensory information-an important factor in ontogeny. Zhurnal Vysshey Nervnoy Deyatel'nosti I. P. Pavlova 47(2):299-307.

Sadaka Y., Lev D. L., Weinfeld L., and White E. L. 2000. Effects of sensory deprivation on the development of asymmetrical synapses in mouse barrels. Somatosensory and Motor Research 17(3):245-254.

Shishelova A. Y., Aliev R. R., and Raevskii V. V. 2016. Effect of early sensory experience on the exploratory activity in adult animals. Doklady Biological Sciences 468(1):101103. https://doi.org/10.1134/S0012496616030029

Shishelova A. Y. and Raevskii V. V. 2010. Effects of vibrissectomy during early postnatal ontogenesis in rat pups on behavioral development. Neuroscience and Behavioral Physiology 40(6):671-677. https://doi.org/10.1007/ s11055-010-9310-8

Shishelova A. Y. 2006. Effect of whisker removal on defensive behavior in rats during early ontogenesis. Neuroscience and Behavioral Physiology 36(8):883-888. https://doi.org/10.1007/s11055-006-0102-0

Sitnikova E. Y. 2001. Vibrissectomy during early ontogenesis in rats disturbs the functional properties of cortical projection neurons. Neuroscience and Behavioral Physiology 31(2):153-156.

Sitnikova E. Y. 2010. The Effect of Early Sensory Experience on the Development of Functional Properties of Neurons in the Area of Vibrissal Projection in Rats' Neocortex. Zhurnal Vysshey Nervnoy Deyatel'nosti I. P. Pavlova. 60(6):719-729.

Symons L. A. and Tees R. C. 1990. An examination of the intramodal and intermodal behavioral consequences of long-term vibrissae removal in rats. Developmental Psychobiology 23(8): 849-867. https://doi.org/10.1002/ dev.420230807 